\title{
The model based on modified Shapley in Partnering mode of profit distribution
}

\author{
Shurong Tan \\ Water conservancy and Environmental Sciences \\ China Three Gorges University \\ Yichang China \\ Tsr3309@sina.cn
}

\author{
Chuanyu Ye Ruixue Ren SongLing \\ Water conservancy and Environmental Sciences \\ China Three Gorges University \\ Yichang China \\ gucaoxibeilang@163.com
}

\begin{abstract}
This paper put forward the new method of Partnering mode for the profit distribution of supply chain is not reasonable and can not reach the global optimization. The Shapely Method is modified to set up a reasonable model by simplified AHP (Analytic Hierarchy Process) method. This model realize in the possibility of operation with complicated factors and the global optimization in the true sense. It has a broad prospect of application.
\end{abstract}

Keywords-profit distribution;global optimization; Partnering model ;Shapley method; AHP method

\section{INTRODUCTION}

With the economic global integration, the real competition isn't between enterprises, but between the supply chain ${ }^{[1]}$, and the parties of supply chain are focus on the distribution of profit. But the function of interest subjects in supply chain is split in the traditional supply chain management mode, and all parties pursuit maximum profit. The global optimization can't be realized under optimal allocation of total resource.

While Partnering mode can solve this problem and it is the long-term commitment relationship between two or more organizations, through the best utilization of the resources of all participants to achieve specific business objectives. Based on fully considering the interests of all parties and identifies common project goal, builds a working group, timely communication, it can avoid the occurrence of dispute and litigation, foster good mutual cooperation working relationship, to solve the problems in the project, share the risks and costs, in order to make in the realization of the aim of the project at the same time also ensure that all parties involved in are realize their target interests ${ }^{[2]}$, and realize the global optimization.

In general the thesis which use Shapely value method to determine the allocation of profits often do not consider the main influence factors of the Shapely value, but this paper considers trust level, information sharing, risk magnitude and commitment which are important factor for Partnering mode running. Combining with specific factors and using the simplified AHP method to correct Shapely value can make profit distribution more practical operability.

A. The inflence factor of stakeholder's interests
distribution in Partnering model

1) the basic principle of income distribution proportion
More win rules must be abided. Profit is common purpose of the partner, only in that the partners "profitable", can form cooperation and trust relationship between them. Incentive mechanism about promote partner income fair distribution must be establish.

Implement a dynamic income distribution mechanism, not only ensure partners "profitable", but also should ensure that the gain of the partners is proportional to the risk and investment it take ${ }^{[3]}$.

To sum up, two principles of income distribution have draw between partners under Partnering mode as follows:

- Partner' gain should proportional with the risk who takes.

- According to more win rules, the project benefits should all shared by the partners and can't part of the partners share all of the earnings, the others have no.

2) The influence factors of interest distribution for core stakeholders

a) Trust level:

Under the mode of Partnering management, in an atmosphere of mutual trust it can reduce the consumption of time and energy in processing claims, contract dispute of traditional mode. The higher the level of trust, cooperation is easy to produce, and maintain the long time.

b) Sharing information:

Make full use of all information to solve the actual problems arising during progress to realize mutual interests, achieve win-win situation.

c) The factor of commitment :

Commitment must be made by the top manager of the participated parties, and form a Partnering agreement. It is a way to implement and management contract, also countermeasures to deal with the relationship between the parties during the Contract period.

d) The factor of risk:

A claim or legal action between the parties can be avoid or reduced and realize reasonable share of the profit and risk by introduce Partnering model in project. But this does not mean risks not exist or the overall risk reduced.

\section{B. The model of profit distribution based on modified} Shapely in Partnering mode

1) The organizational structure of Partnering model 
Structure flow chart shows as follow picture:

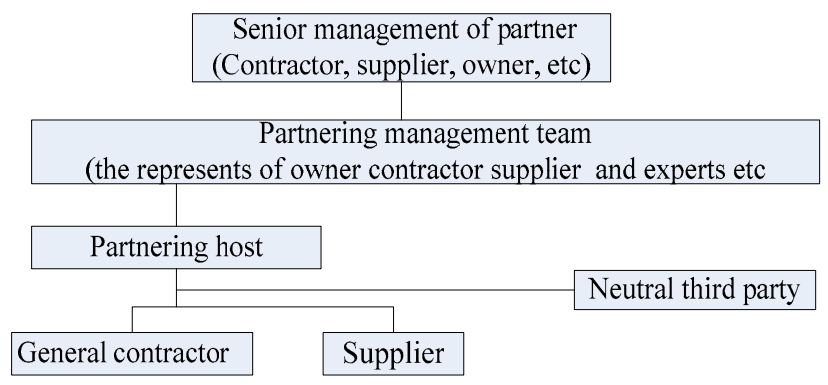

First, in the working process the owner chooses cooperation partners to participate in the Partnering model. And this paper mainly considers the general contractor and supplier.

Secondly, partner senior management select qualification management representative of the parties established Partnering management team, to conclude the common goal of the organization as well as the relevant plan.

Then, appoint the Partnering host to responsible for the entire Partnering model establishment and implementation by all participated parties.

Finally, participants discuss with Partnering host to formulate Partnering agreement which includes the common goal of all parties and establish Partnering model dispute processing and evaluation system. Among them, the Partnering host responsible for Partnering agreement implements and in the later coordinate the Partnering meeting. If the economy allows, the Partnering organization can choose a neutral third party which accept by each other to supervise the whole working process, when a dispute can't be coordinated or solved by participants themselves in the process of project implementation, the neutral third party can solved it.

2) The calculation method of income distribution proportion

a) Determination of Shapely value ${ }^{[4]}$

Shapely value method is a mathematical method put forward by Shapely 1. s. in 1953 to solve the countermeasure of many people cooperation (Cooperative $\mathrm{n}$ - person game). When benefit activities is non-confrontational between them, benefit will not be reduced as the number of cooperator increasing, like this, all the cooperation of $N$ personal will bring the greatest benefits and Shapely value is a kind of method to distribute it

Assume that $N$ is a collection of participants $S \in N$ is a subset of $N$ and $V(s)$ is defined as the characteristic function of the subset. $S$ Stand for income, set $\varphi_{i}$ as profit of $i$ involved in the cooperation, and then meets the following conditions:

$$
\sum_{i=1}^{s} \varphi_{i}=v(s) \quad v(s)>\sum_{i \in s} v(i)
$$

According to shapely theory it can get:

$$
\begin{gathered}
\varphi_{i}=\sum_{s \in s_{i}} \omega(|s|)[v(s)-v(s \backslash i)] \\
\omega(|s|)=\frac{(n-|s|) !(|s|-1) !}{n !}
\end{gathered}
$$

In the formulas: $\omega(|s|)$ is weighted factor, $|S|$ stand for the size of the subset, i.e., the number of members; $S_{i}$ are all subset who contains $i$ in set of $s$, the $v(s \backslash i)$ of $[v(s)-v(s \backslash i)]$ stand for the income after removing $i$ from subset $s$, So $[v(s)-v(s \backslash i)]$ can be regarded as member $i$ contribute to the alliance of $s$.

Because the participants of Partnering model are the owner, the general contractor and supplier, so in the calculation profit distribution shapely value process suppose $i=1.2 .3$ respectively stand for it; $N=\{i\}$ said $N$ is the set of $i$ so at here $N=3, \varphi_{1}, \varphi_{2}$ and $\varphi_{3}$ respectively stand for the income of the owner, the general contractor and supplier got before revise.

b) Modify the shapely value by simplified AHP

By the analysis above we can know though the shapely value method have avoid average distribution of interests and have certain science, but this allocation scheme default consider the influence degree of them is equalization as: 1 / $\mathrm{n}$. Therefore, we need to modify the shapely value.

Analytic Hierarchy Process is the decision-making method which bases on breaking the element of decision down into some level such as goals, standards, scheme and then to qualitative analysis and quantitative analysis. The characteristics of AHP is used less quantitative information to make the decision process mathematical basing on deep analysis complicated factors, thus it provides easy decision method for the complex decision problem which have more goal, criteria or no structural characteristics. Especially it is suitable for the occasions when accurate measurement is difficult to directly decide for results.

The Partnering model in this paper employ AHP method can link each factors themselves and main body, use the relative importance of factors, namely combined consideration the qualitative and quantitative, can avoid the disadvantages of isolate each factors as before. Given under the shapely value and considering influence factors of interests distribution, correction factor set $\left[a_{1}, a_{2}, a_{3}, a_{4}\right]$ respectively present the risk magnitude of key factor, trust level, promises, quantity of information sharing, $\mathrm{P}$ present the gross profit, and $A_{1}, A_{2}, A_{3}$ respectively present the owner, the general contractor and supplier. According to the AHP theory, we will set distribution of gross profit as goal, the second is influencing factors, and the third layer for profit distribution subject, as below: 


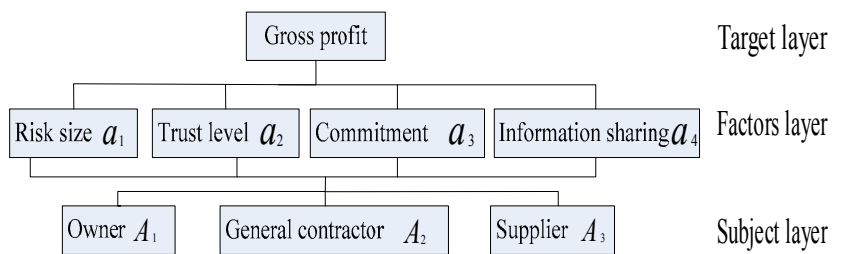

Through the expert analysis compared the important degree of each two factors and judgment matrix be structured, $S_{i j}^{a}$ be given as for $a$ and the degree of $i$ is important than $j$. Such as to the gross profit the important degree of risk magnitude to trust level is $S_{a_{1} a_{2}}^{p}$.Aiming at target layer and according to each factor of the factor layer's influence on the total profits $p-a$ judgment matrix be established; contrapose factor layer and according to the influence of each factor on different subjects establish matrix $a_{1}-A, a_{2}-A, a_{3}-A, a_{4}-A$. Use $p-a$ as an example and the judgment matrix figure as following:

\begin{tabular}{|c|c|c|c|c|}
\hline Target P & $a_{1}$ & $a_{2}$ & $a_{3}$ & $a_{4}$ \\
\hline$a_{1}$ & 1 & $S_{a_{1} a_{2}}^{p}$ & $S_{a_{1} a_{3}}^{p}$ & $S_{a_{1} a_{4}}^{p}$ \\
\hline$a_{2}$ & $S_{a_{2} a_{1}}^{p}$ & 1 & $S_{a_{2} a_{3}}^{p}$ & $S_{a_{2} a_{4}}^{p}$ \\
\hline$a_{3}$ & $S_{a_{3} a_{1}}^{p}$ & $S_{a_{3} a_{2}}^{p}$ & 1 & $S_{a_{3} a_{4}}^{p}$ \\
\hline$a_{4}$ & $S_{a_{4} a_{1}}^{p}$ & $S_{a_{4} a_{2}}^{p}$ & $S_{a_{4} a_{3}}^{p}$ & 1 \\
\hline
\end{tabular}

- Calculate the product of each row element in matrix $p-a$ and Set $M_{k}$ respectively, namely:

$$
M_{k}=\prod S_{a_{k} a_{i}}^{p} \quad(k=1.2 .3 .4 i \neq k)
$$

- $\quad$ calculate the three root- $\overline{M_{k}}$ of $M_{k}$ :

$$
\overline{M_{k}}=\sqrt[3]{M_{k}} \quad(k=1.2 .3 .4)
$$

- Normalize and get features value $\omega_{k}$ :

$$
\omega_{i}=\overline{M_{i}} \div \sum_{j=1}^{4} M_{j} \quad(i=1.2 .3 .4)
$$

That the relative weight vector of factor $a$ to $p$ is $\omega_{p-a}=\left(w_{1}, w_{2}, w_{3}, w_{4}\right)^{T}$

Similarly, the other judgment matrix level sequence can be calculate and get a hierarchical order list, as the chart:

\begin{tabular}{|c|c|c|c|c|c|}
\hline $\begin{array}{c}\text { level } \\
\text { and }\end{array}$ & $a_{1}$ & $a_{2}$ & $a_{3}$ & $a_{4}$ & $\begin{array}{c}\text { K the } \\
\text { sort of } \\
\mathbf{A}\end{array}$ \\
\cline { 2 - 5 } & $\omega_{1}$ & $\omega_{2}$ & $\omega_{3}$ & $\omega_{4}$ & \\
\hline $\mathrm{A}_{1}$ & $\omega_{1}^{\prime}$ & $\omega_{1}^{\prime \prime}$ & $\omega_{1}^{\prime \prime \prime}$ & $\omega_{1}^{\prime \prime \prime \prime}$ & $\kappa_{1}$ \\
\hline
\end{tabular}

\begin{tabular}{|l|l|l|l|l|l|}
\hline $\mathrm{A}_{2}$ & $\omega_{2}^{\prime}$ & $\omega_{2}^{\prime \prime}$ & $\omega_{2}^{\prime \prime \prime}$ & $\omega_{2}^{\prime \prime \prime \prime}$ & $\kappa_{2}$ \\
\hline $\mathrm{A}_{3}$ & $\omega_{3}^{\prime \prime}$ & $\omega_{3}^{\prime \prime}$ & $\omega_{3}^{\prime \prime \prime}$ & $\omega_{4}^{\prime \prime \prime \prime}$ & $\kappa_{3}$ \\
\hline
\end{tabular}

And $\kappa_{1}=\omega_{1} \times \omega_{1}^{\prime}+\omega_{2} \times \omega_{1}^{\prime \prime}+\omega_{3} \times \omega_{1}^{\prime \prime \prime}+\omega_{4} \times \omega_{1}^{\prime \prime \prime \prime}$, others similarly the weight $k=\left(k_{1}, k_{2}, k_{3}\right)^{T}$ of each factor can be getting after revised, so the profit distribution of each main body after the amendment is:

$$
\varphi_{i}^{\prime}=\varphi_{i}+\left(\kappa_{i}-\frac{1}{n}\right) \times v(s)
$$

\section{SUMMARY}

The deficiency of this paper is the determined method for the relative importance of factors is great influenced by human factor and little considering the factor of profit distribution, while there are many influencing factors in actual engineering project. Though Partnering is a new kind of management mode in international, but it have certain application premise: first, the parties adopt voluntary principle; second, Partnering mode has certain requirements for the type of project; third, there is a gap between our project management level and abroad. So, at present it is rarely applied in our country, but along with our country economy accelerated integrating into the global economy, the advantages of Partnering mode is gradually recognized and it is urgent to be introduced into our engineering construction field. These show that the Partnering mode has a broad prospect of application in our country.

[1] Martin Christopher (1992), Logistics and Supply Chain Management, Pitman Publishing.

[2] Yibao Yue. The new model of International engineering project management - Partnering model [J]; Architectural, 2003, (4).

[3] ChenXiao: "Study on the Proportion Making for Profit Allocation within Partnering Project"[J]; The value engineering,2001 (5).

[4] Hu li, Weiguo Zhang, Xiaosu Ye: "Profit allocation of PPP model based on the revised SHAPELY "[J]; Journal of Industrial Engineering and Engineering Management, 2011 (2)

[5] Saaty TL. Analytical Hierarchy Process [M].Translated by XuShu-bai. Beijing: China Coal Industry Publishing House, 1988. 